\title{
Patterns of Otorhinolaryngological Disorders in Subjects with Diabetes
}

\author{
Gazzaz ZJ, Makhdom MN, Dhafar KO, Maimini O, Farooq MU, Rasheed A
}

Al-Noor Specialist Hospital, Makkah, Saudi Arabia

\begin{abstract}
Objective: To find out the prevalence of otorhinolaryngological disorders in patients with diabetes mellitus who presented to Ear, Nose and Throat (ENT) clinic at Al-Noor specialist hospital, Makkah, Saudi Arabia. Materials \& Methods: This observational retrospective study was carried out over a period of one year, from July 15, 2004 to July 20, 2005 by the collaboration of ENT Department and Health Research Center of Al-Noor Specialist Hospital, Makkah, Saudi Arabia. Patients' information was collected such as the demography, types and durations of diabetes, types of diabetic treatments, and final ENT diagnosis. Subjects' random blood sugar and hemoglobin A1c (HbA1c) levels were collected on the first visit to the ENT-Outpatient Department. Results: One hundred patients met the inclusion criteria; with mean age of 51.5 years (age range 14-86 years). Thirty-nine percent of the patients were at the age of 45-54 years old. Males (52\%) slightly out-numbered the females. Majority had diabetes mellitus type 2 and 78\% patients had high HbA1c levels indicating poor glycemic controls. The most common ENT disorder was rhinitis (19\%), followed by sensorineural hearing loss $(12 \%)$ and malignant otitis externa $(8 \%)$. Conclusion: The most common ENT disorder in patients with diabetes mellitus type 2 was rhinitis, followed by sensorineural hearing loss. Majority of these patients had poor glycemic control, hence can explain the predominance of certain disorders over others.
\end{abstract}

KEYWORDS: Diabetes mellitus, otorhinolaryngologic diseases, rhinitis, hearing loss

\section{INTRODUCTION}

Among the most common chronic disorders of modern time, diabetes mellitus (DM) remains unique because of its multisystem ramifications. ${ }^{1}$ Type 2 DM is a complex disease with both metabolic and vascular components that affects about 285 million worldwide in 2010 and will rise to 438 million at the end of 2030 with age group of $20-70$ years. ${ }^{2}$ Prevalence of DM is $10.2 \%$ in western pacific to $3.8 \%$ in African region. ${ }^{3} \mathrm{DM}$ is a major public health problem in the Kingdom of Saudi Arabia (KSA). Its prevalence is on the increase, being as high as $23.7 \%$ among adult citizens. ${ }^{4}$

Type 2 DM is associated with a number of microvascular complications affecting most commonly the eyes and kidneys, and histopathological studies have shown damages to the nerves and vessels of the inner ear of individuals with diabetes. ${ }^{5,6}$ Necrotizing (malignant) external otitis, an infection involving the temporal and adjacent bones, is a relatively rare but dangerous complication of external otitis. ${ }^{7}$ Cutaneous infections, which may be bacterial, fungal

Corresponding author:

Dr. Mian Usman Farooq

Health Research Centre

Performance Measurement Manager

King Abdullah Medical City,

Muzdallifa, Makkah, Saudi Arabia

P. O. Box 57657, Zip code=21955

Email:drus76@yahoo.com, hrd_alnoor@yahoo.com or viral, are common among patients with diabetes, ${ }^{8}$ and can affect the skin and soft-tissue structure of the ear and the nose as well.

To the best of our knowledge, the prevalence of otorhinolaryngological disorders in patients with diabetes has not been properly documented. Our study highlighted the prevalence of otorhinolaryngological disorders in the diagnosed patients of DM in a hospital setting in Saudi Arabia.

\section{MATERIALS AND METHODS}

This was an observational retrospective study, carried out over a period of one year from July 15, 2004 to July 20, 2005. The study was conducted at the Ear, Nose and Throat-Outpatient Department (ENT-OPD) of Al-Noor Specialist Hospital, Makkah, Saudi Arabia. It was done by the collaboration of ENT Department and Health Research Center of the hospital.

The study population was from the diabetic patients who visited the ENT-OPD of the hospital within the period of study. The diabetic patients who visited the ENT-OPD during the said period were identified, and their files were retrieved from the medical record unit for data extraction. Data had been retrospectively collected in a preformed questionnaire by a medical research officer of the Health Research Centre. Patients' information was collected for demography (age and gender), types of diabetes, duration of diabetes, types of diabetic treatment, and final diagnosis of patients done by the specialist in the ENT-OPD Clinics. Subjects' random blood-sugar levels and $\mathrm{HbA} 1 \mathrm{C}$ levels were collected on the first 
visit to ENT-OPD during the study period. The ages were grouped into 15-24, 25-34, 35-44, 45-54, 55-64, $65-74$, and $>74$ years. The duration of diabetes was divided into $<10,11-20$ and $>20$ years, and diabetic treatment type was categorized as oral, injectable, both and no treatment. One patient was counted as one regardless of his frequency of visits. The levels of random sugar above $200 \mathrm{mg} / \mathrm{dl}$ and $\mathrm{HbA} 1 \mathrm{c}>7 \%$ were taken as uncontrolled/high respectively. ${ }^{9}$

Al-Noor Specialist Hospital is a tertiary care referral teaching hospital with 550 beds in Makkah City and serving the population for about more than 18 years. The study was approved by the Institutional Review Board of Al-Noor Specialist Hospital.

\section{Statistical analysis}

Data was analyzed using Microsoft Office Excel (version 2007). Numerical data was subjected to descriptive analysis, with mean \pm standard deviation (SD) range. Categorical data was analyzed as requency and percentage.

\section{RESULTS}

During the period, 100 patients met the inclusion criteria for this study. Males (52\%) were slightly predominant than females. Overall subjects' mean age was 51.5 (14-86) years, while mean age of the male subjects was $51.2(20-86)$ years and the females at $51.8(14-78)$ years. The majority belonged to the age group of 45-54 years followed by 55-64 years (Table I).

\begin{tabular}{|c|c|c|c|}
\hline \multicolumn{4}{|c|}{ Table I. Demographical Data of Subjects } \\
\hline $\begin{array}{c}\text { Age groups } \\
\text { (Years) }\end{array}$ & Male & Female & Total \\
\cline { 2 - 4 } & $\mathrm{n}(\%)$ & $\mathrm{n}(\%)$ & $\mathrm{n}(\%)$ \\
\hline $15-24$ & $2(2)$ & $3(3)$ & $5(5)$ \\
\hline $25-34$ & $2(2)$ & $1(1)$ & $3(3)$ \\
\hline $35-44$ & $5(5)$ & $6(6)$ & $11(11)$ \\
\hline $45-54$ & $19(19)$ & $20(20)$ & $39(39)$ \\
\hline $55-64$ & $14(14)$ & $14(14)$ & $28(28)$ \\
\hline $65-74$ & $7(7)$ & $3(3)$ & $10(10)$ \\
\hline$>75$ & $3(3)$ & $1(1)$ & $4(4)$ \\
\hline Total & $52(52)$ & $48(48)$ & $100(100)$ \\
\hline
\end{tabular}

The mean duration of diabetes was 11.9 years. There were 90 type 2 diabetic patients. Half of the subjects had the duration of diabetes of less than 10 years. Oral hypoglycemic therapy was used by $52 \%$ of patients while $5 \%$ was on both oral and injectable therapy. On the other hand, $51 \%$ patients had no glycemic control while HbA1c level was high in $78 \%$ patients (Table II).

\begin{tabular}{|c|c|c|c|c|}
\hline \multicolumn{5}{|c|}{$\begin{array}{l}\text { Table II. Distribution of characteristics of study subjects } \\
\text { features of diabetes }\end{array}$} \\
\hline \multicolumn{3}{|c|}{ Variables } & $(n=100)$ & $\%$ \\
\hline \multirow{2}{*}{\multicolumn{2}{|c|}{ Diabetic Type }} & 1 & 10 & 10 \\
\hline & & 2 & 90 & 90 \\
\hline \multirow{3}{*}{\multicolumn{2}{|c|}{$\begin{array}{l}\text { Duration of } \\
\text { Diabetes }\end{array}$}} & $\leq 10 \mathrm{yrs}$ & 50 & 50 \\
\hline & & $11-20$ & 40 & 40 \\
\hline & & $>20$ & 10 & 10 \\
\hline \multirow{4}{*}{\multicolumn{2}{|c|}{$\begin{array}{l}\text { Diabetic Treatment } \\
\text { Type }\end{array}$}} & Oral & 52 & 52 \\
\hline & & Injection & 40 & 40 \\
\hline & & Both & 5 & 5 \\
\hline & & No Treatment & 3 & 3 \\
\hline \multirow{5}{*}{$\begin{array}{l}\text { Diabetic } \\
\text { Control }\end{array}$} & \multirow{2}{*}{$\begin{array}{l}\text { Blood } \\
\text { Sugar } \\
\text { Level }\end{array}$} & Controlled & 49 & 49 \\
\hline & & Uncontrolled & 51 & 51 \\
\hline & \multirow{3}{*}{$\begin{array}{l}\text { HbA1C } \\
\text { Level }\end{array}$} & High & 78 & 78 \\
\hline & & Normal & 13 & 13 \\
\hline & & Not done & 9 & 9 \\
\hline
\end{tabular}

Majority of the ENT disorders were rhinitis (19\%) followed by sensorineural hearing loss (12\%) (Table III).

\begin{tabular}{|l|c|c|}
\hline \multicolumn{3}{|c|}{ Table III. Distribution of DM patients by type of ENT disorder } \\
\hline Diagnosis & no & $\%$ \\
\hline Rhinitis & 19 & 19 \\
\hline Sensorineural hearing loss & 12 & 12 \\
\hline Chronic supporative otitis media & 11 & 11 \\
\hline Otomycosis & 9 & 9 \\
\hline Vertigo & 9 & 9 \\
\hline Otitis Externa & 8 & 8 \\
\hline Pharyngitis & 7 & 7 \\
\hline Epistaxis & 6 & 6 \\
\hline Frunculosis Sinusitis & 4 & 4 \\
\hline Wax & 4 & 4 \\
\hline Sinusitis & 2 & 2 \\
\hline Vocal paralysis & 7 & 7 \\
\hline *Miscellaneous & & \\
\hline
\end{tabular}




\section{DISCUSSION}

Our study showed that rhinitis was the predominant ENT disorders in cases of diabetes. This condition is not the proven consequences or complication of $\mathrm{DM}$, but its predominance may be related with the prevalence of uncontrolled DM in the study subjects. The immune-compromised status of subjects with uncontrolled DM renders them more prone to any acute or chronic inflammatory viral or bacterial infections. On the other hand, $24 \%$ of the cases were diagnosed as sensorineural hearing loss, otitis externa and furunculosis, which are related to uncontrolled or poorly controlled DM. ${ }^{10-14}$ Majority of otomycosis cases are prevalent in the hot and humid environment, ${ }^{15}$ like in eastern province of Saudi Arabia. However, in Makkah, the environment is hot but not humid. Other predisposing factors for otomycosis, such as bacterial infection, broad-spectrum antibiotics usage, self-inflicted trauma, swimming, steroids usage and failure of ear defence mechanism might be the reason here.

Both hypo- and hyperglycemia have been associated with inner ear dysfunction and hearing may fluctuate with blood-glucose levels. ${ }^{16}$ The relationship between DM, sensorineural hearing loss and vestibular dysfunction has been known for sometimes and histopathological changes in the temporal bone have been clearly documented. ${ }^{17}$ But, according to one study, there was a weak association between diabetes and hearing loss. ${ }^{4}$ Taylor and Irwin noted that patients with diabetes as a whole were deafer particularly in the lower frequencies than the controls, gradually approaching each other in the middle range $(1-4 \mathrm{kHz})$ and were similar at $8 \mathrm{kHz} .{ }^{18}$ Friedman and Schulman studied 20 diabetic patients with peripheral neuropathy. ${ }^{19}$ They concluded that $55 \%$ of their subjects had symmetrical hearing loss of the sensorineural type, involving at least one frequency, although none gave a history of hearing loss and ear diseases. The hearing loss was unrelated to age, and the impairment was similar at low and high frequencies, with a maximum deficiency between 750 and $2000 \mathrm{~Hz} .{ }^{19}$ A small group of patients with idiopathic sudden hearing loss was investigated to study the possibility of a relationship with diabetes but no correlation was found in the audiological pattern. However, patients with diabetes failed to recover as well in high-frequency loss compared to non diabetic patients. ${ }^{10}$

Invasive otitis externa affects predominantly those over fifty years of age and most patients have evidence of micro vascular disease such as DM. ${ }^{11}$ Poorly controlled diabetics have a greater susceptibility to bacterial and fungal infections of the skin, such as furunculosis and carbuncles. ${ }^{14,20}$ In the preinsulin era, the prevalence of common pyodermas such as furunculosis, carbunculosis, and erysipelas was much higher in patients with diabetes than for their non-diabetic counterparts. ${ }^{20} \mathrm{~A}$ study by Naheed et al. ${ }^{21}$ of diabetic patients who admitted in medical wards with different problems had shown that $62.2 \%$ of them had skin infections, and this was contrary to ours. In their study, the subjects' mean and age range and the prevalence of type II DM subjects were greater than our study.

The duration of diabetes is an important factor that determines the appearance of microvascular complications of diabetes. It seems that the longer duration of DM predisposes more to the development of deafness in many studies, however, mild degree of hearing impairment was detected in many children with diabetic duration of less than four years. ${ }^{22}$ Such observation was unusual and might be explained by poor glycemic control. Elamin et al. have proven the relationship of hearing loss in children and adolescent with type 1 DM at middle and high frequencies, which was not present in their controls. ${ }^{22}$

This is an observational study, institutional based and not community based study. Thus, it cannot prove the true relationship of DM with otorhinolaryngological disorders. Being the observational study, we cannot measure the odds ratio or relative risk ratio of the relation between ENT disorders and DM, controlled or uncontrolled. Moreover, the study duration and the subject numbers were too small to conclude any association other than just the descriptive findings. A case-control study is recommended to test the association.

\section{CONCLUSION}

The most common ENT disorder in patients with diabetes mellitus type 2 was rhinitis, followed by sensorineural hearing loss. Majority of these patients had poor glycemic control. This may explain why certain disorders were more prevalent than others. There should be a case-control study to define the relation of DM and otorhinolaryngological disorders.

\section{REFERENCES:}

1. Amos AF, McCarty DJ, Zimmet P. The rising global burden of diabetes and its complica tions: estimates and projections to the year 2010. Diabet Med 1997;14: S1-85.

2. International Diabetes Federation (Belgium). In: Diabetes facts and figures (online). Avail able from: http//www.idf.org/diabetesfacts-and-figures. Accessed Oct 28, 2010.

3. Diabetes facts-World Diabetes Foundation. Available at: httpllwww.worlddiabetesfoun dation.org/composite-35.htm. Accessed June, 2011.

4. Al-Nozha MM, Al-Maatouq MA, Al-Mazrou YY, et al. Diabetes mellitus in Saudi Arabia. Sau di Med J 2004; 25(11):1603-10.

5. Dalton DS, Cruickhanks KJ, Klein R, Klein BEK, Wiley TL. Association of NID DM and hearing loss. Diabetes Care 1994; 17:1158-63. 
6. Jordao AMD. Consideration sur un cas du diabete. Union Medicale Paris 1857; 11:446. [English translation]

7. Handzel O, Halperin D. Necrotizing (Malignant) External Otitis. Am Fam Physician 2003; 68: 309-312.

8. Schwartz B, Schuchat A, Oxtoby MJ. Invasive group B streptococcal disease in adults. A population based study in metropolitan Atlanta. JAMA 1991; 266:1112-14.

9. Seurez L. New ADA recommendations more comprehensive. Available at: http//www.dia beticmctoday.com/HtmlPage/DMC0305/ PDFs/Clark.pdf. Accessed June, 2010

10. Wilson WR, Laird N, Soeldner JS, Moo-young G, Kaveshi DA, Macmeel JW. The relationship of idiopathic sudden hearing loss to diabetes mellitus. Laryngoscope 1982; 92:155-160.

11. Necrotising otitis externa. Lancet 1982; 319:207. doi:10.1016/S0140-6736(82)907693.

12. Meltzer P, Kelemen G. Pyocyaneus osteomy elitis of temporal bone, mandible and zygoma. Laryngoscope 1959; 69:1300-16.

13. Chandler JR. Malignant external otitis. Laryngoscope 1968; 78:1257-94.

14. Sreedevi C, Car N, Pavlic-Renar I. Dermatolog ic lesions in diabetes mellitus. Diabetol Croat 2002; 3:147-159.

15. Pontes ZBVS, Silva ADF, Lima EO, et al. Otomycosis a retrospective study.

Braz J Otorhino laryngol (seri al online) 2009:75367-370.

Available from:http//www.scielo.br/ scielo.php?script=sci_arttext\&pid=\$1808$86942009000300010 \& \operatorname{lng}=e n$. Accessed October 30, 2010.

16. Rudd MJ, Harrie ML, Lynch CA, Moffat DA. Hearing loss fluctuating with blood sugar levels in meniere's desease. J Laryngol Otol 1993; 107:620-622.

17. Moffat DA, Booth JB, Morrison AW. Metabolic investigations in meniere's disease. $J$ Laryngol Otol 1981; 95:905-913.

18. Taylor IG, Irwin J. Some audiological aspects of diabetes mellitus. J Laryngol Otol 1978; 92: 99-113.

19. Friedman SA, Schulman RH. Hearing and diabetic nephropathy. Arch Inter Med 1975; 135:573-576.

20. Huntley A. Diabetes Mellitus Review. Derma tology (Online) 1995:1. Available at: http// dermatology.cdlib.org/DOJvol1num2/ diabetes/dmreview.html. Accessed October 30, 2010.

21. Naheed T, Akbar N, Akbar N, Shehzad M, Jamil S, Ali T. Skin manifestations amongst diabetic patients admitted in a general medical ward for various other medical problems.Pak J Med Sci 2002; 18:291-296.

22. Elamin A, Fadlallah M, Tuvemo T. Hearing loss in children with type 1 diabetes. Indian pediatrics 2005; 42:15-21. 